\title{
Health, wellness and society \\ Dialogue between discourses and physiological effects on well-being in yoga practices
}

\author{
Caroline Nizard, ${ }^{1}$ Lausanne University, Institut d'histoire et anthropologie des religions, \\ Switzerland
}

\begin{abstract}
Many medical studies demonstrate the benefits of yoga; however social sciences focus more rarely on the links between yoga and well-being. Starting from an anthropological approach, this article presents a study that connects the subjective discourses of yoga practitioners with the objective data on well-being (through heart and respiratory rates). Save for the presentation of this experimentation, the discussion will allow us to discover the contribution of each approach, but also to emphasize the variations according the level and the type of received with practitioners having learnt the same breathing technique.
\end{abstract}

Keywords: yoga, well-being, feeling, discourses, physiological effects, interdisciplinary

"I will always remember my feelings after my first yoga class. I felt high, completely light, in a state I had never felt in my life, yet. I did a lot of pleasant activities, like everyone else. It is a state I aspire to in every class and that I can't always attain. It is a combination of clear-headedness and a lightness. The feeling of being present to my body, to what is within me, a perfect union between my body and my mind. It is a physical and mental well-being. " (Alice, 35 years old, practitioner, French)

1 consensus seems to be emerging from the practices of contemporary yoga and it's called well-being. Alice links this well-being to "being present at [her] body", to "feeling light" and to an impression of "union between [her] body and [her] thoughts". She testifies to her experience of well-being, a feeling shared by all the practitioners I have met. Practising yoga myself, without being a teacher, from the beginning of my research, I was struck by this unanimity related to the association of yoga and well-being.

How could we define this "well-being"? Is it a feeling? Is it linked to beliefs or representations attached to yoga? Is it related to the learning of specific techniques in yoga such as postures, meditation or breathing techniques? Is something physiologically happening? What is the role of the teacher? These questions were at the basis for an interdisciplinary approach and experimentation that aimed to try to link expressed well-being with some physiological data and resorted to three levels of analysis: (a) physiological (objective data), (b) psychological and (c) anthropological (subjective data). This article will take stock of the studies dedicated to the wellbeing in yoga, focusing on the methods for synthesizing the experimentation carried out, and on the results obtained. Finally, it will open a discussion on the differences and similarities between objective and subjective data.

\footnotetext{
${ }^{1}$ Caroline Nizard, Ruelle de la Fonjalla 2, 1663 Pringy, Switzerland, email : nizard.caroline@gmail.com
} 


\section{Combined objective and subjective data on well-being}

\section{Anthropological and medical perspectives on well-being in yoga}

The umbrella term YOGA comes from the Sanskrit yug, which means "union", "bond", or "hitch" and has known a wide range of interpretations and appropriations through history, making it fluctuate between a goal (to get out of the cycle of reincarnations for the Hindus) and a means (with a range of techniques). In contemporary yoga, and in the context of this study, yoga will be understood as a psycho-bodily method that mobilizes physical and mental exercises in order to achieve a kind of self-perfection tinged with physical asceticism, health and/or esotericism (Hauser, 2013).

Works of historians (White, 2011, Samuel, 2008, Alter, 2004, De Michelis, 2005), sanskritists (Birch, 2011, Mallinson, 2017, Mass, 2013, Singleton, 2017) or sociologists (Altglas, 2005, Hoyez, 2012, Bevilacqua, 2019) are increasing on yoga, well-being remains relatively unexplored in the scientific literature (Newcombe, 2019), despite the abundant popular representations connecting yoga and well-being. Historically, the benefits of yoga on health were already present in ancient texts, today perceived as canonical in yoga circles (such as Hațha Yoga Pradīpikā, $15^{\text {th }}$ century). It was not until the 1920 s that some research in India seemed to demonstrate these benefits. Over the past twenty years, several authors have described an increase of interest in the health/therapeutic dimension in yoga practices (Hauser, 2013, Strauss, 2005, Newcombe, 2019, Hoyez, 2012) in India, the United States and Europe. Moreover, in India, as in the United States, neuroscientific or medical works are abundant on the subject.

The objective of medical studies is to evaluate the impact of postures, meditation (Dinesh, 2013, Jerath [et al.], 2012) or breathing techniques on the brain (Cameron, 2001, Price, Hooven, 2018), blood pressure (Tripathy, Sahu, 2019), concentration (Saraswati, 2009) and on certain diseases (diabetes, asthma, cardiovascular diseases in particular). Among these studies, the most focus on the positive effects of yoga postures or meditation (Brown, Ryan, 2003, Mehling, Gopisetty, Daubenmier, Price, 2009).

However, breathing techniques remain at the heart of any yoga practice. This is one of the reasons why this study focused more on these techniques (named prānāyāma). The other reason is that other relaxation methods (biofeedback, autogenous training, Alexander method or hypnosis) also use breathing as a regulatory mode leading to relaxation. All this literature shows that some technical mastery, as well as a simple awareness of breathing, help to act on the nervous system (see below) allowing to calm down or to manage stress or emotions. Among these studies, the one conducted by Singh, Gaurav and Parkash (2011), Bhimani[et al.] (2011), Cowen and Adams (2005), Subbalakshmi (2005) allowed a comparison with this experiment since they focus on the same breathing technique. However, the originality lies in the fact they have tried to link the discourses of the practitioners to physiological results.

\section{Question of methods}

In this paper, the experiment, lead by the author, involved three levels of method and analysis: (a) anthropological, (b) psychological (subjective data) and (c) physiological (objective data).

Looking at well-being through the prism of social sciences raises questions in terms of the subjective component of this sensation. For this purpose, anthropology (a) uses two tools: semidirective interviews and participant observation. In concrete terms, between 2013 and 2017, sixty interviews $^{2}$ were conducted with practitioners and/or teachers in France (Paris, Orléans,

\footnotetext{
${ }^{2}$ The observation and interview focused on three main elements: (a) life courses (sociological characteristics, primary motivations), (b) the specificities of yoga learning (teacher-student relationship, discourse on the body and sensations,
} 
Ardèche), French-speaking Switzerland (Gruyère and Lausanne) and India (Bangalore, Delhi, in particular). Among these sixty people, twenty-five also participated in the experiment ${ }^{3}$. Participant observation ${ }^{4}$ has taken place in yoga classes, ashram retreats, festivals or conferences in these three countries. In anthropology, the traditional tools of interviews and participant observation help to liberate the speech, to observe similarities or discrepancies between speeches and practices, and to mix formal and informal discussions. For the experiment, the semi-directive interviews allowed to understand the meaning given by the practitioners to well-being, the body and the breath.

Between sensation and verbalization, there may be differences in translation, the psychological method (b) proposed by Pierre Vermersch (1994) appeared as a relevant tool. In his 1994 book, Vermersch developed a method based on psychology, inspired in particular by the work of Varela (1993), with whom he collaborated, and by Husserlian phenomenology. The aim of the explicitation interview is to raise awareness about the thought or gesture process. Indeed, this method has the advantage of helping the person to divide his/her learning into micro actions, and thus to make him aware of the mechanisms during the action. As in psychoanalysis, the mechanism consists in making the subject relive a moment of difficulty in order to try to put into words these mental and/or physical microactions into words. Finally, the explicitation interviews helps to correlate objective data (heart and respiratory rates) with subjective data (discourses).

In another perspective, (c) the cognitive sciences seek to objectify this "well-being", through the dominance of the parasympathetic system ${ }^{5}$ over the sympathetic system, which can be measured by decreasing heart and respiratory rates, lowering blood pressure or by the production of certain neurotransmitters: dopamine, serotonin, endorphin, acetylcholine. Here, the physiological measurements chosen were heart and respiratory rates. In practical terms, an electrocardiogram and a strain gauge were used to collect these data to measure the intervals between R-R peaks and heart rate variabilities ${ }^{6}$, indicators known to observe the dominance of the parasympathetic system.

\footnotetext{
techniques, texts taught and shared vocabulary) and (c) the consequences on the lives of the people encountered (in terms of relationship to the body, oneself, others, environment, nutrition, other sports, spiritual or medical practices). Each interview lasted between one and three hours.

${ }^{3}$ The twenty Indian practitioners did not take part in the experiment and a few people in France and Switzerland were unable to participate for reasons of relocation, pregnancy in particular.

${ }^{4}$ Always presenting myself as a yoga practitioner and a researcher, I was perceived as a member of the community, which allowed me to gain legitimacy with the practitioners in order to free the speeches, especially on beliefs. However, I chose to follow several teachers, yoga classes in order to compare the discourses to objectify the data collected.

${ }^{5}$ The autonomous nervous system regulates automatic functions of the body: digestion, breathing, heart muscles, glands and some hormonal secretions. Its two main components are: the sympathetic nervous system, the parasympathetic nervous system which function antagonistically. The parasympathetic system causes a slowing of the heart rate, a stimulation of bile, digestion or saliva. Conversely, the sympathetic system accelerates the heart rate, stimulates glucose production, inhibits digestion and secretions. Broadly speaking, the sympathetic system prepares the body for action and the parasympathetic system dominates in situations of calm and relaxation.

${ }^{6}$ The heart never beats at a regular rate, so the intervals between two beats fluctuate. Heart rate corresponds to the duration of the contraction of the heart and the variability of the heart rate at the interval between these contractions. Cardiac coherence leads to a synchronization between breathing and heart rate.
} 


\section{Presentation of the technic chosen: nādī sodhana}

To link these two subjective and objective levels of well-being, an experiment was conducted between 2014 and 2016, with twenty-five yoga practitioners (without distinction of levels at the beginning) and a control group of ten sportsmen, but not yoga practitioners. These twenty-five practitioners knew all the techniques chosen ${ }^{7}$. However, only twenty-one of them were able to participate in all the meetings. They were divided into two groups: the first one, in Switzerland ${ }^{8}$, follows a professor, Françoise, whose discourse on yoga is more "spiritual" and the second one, in Paris, follows Mahé, whose discourse more focus on a challenging yoga. These two groups performed these experiments twice, six or nine months apart, while continuing their usual yoga practice in the meantime.

Among these breathing techniques (prānāyāma $a^{9}$ ), the technique of nād $\bar{l}$ sodhana is at the same time the oldest technique and one of the most commonly taught today. The choice was therefore made in agreement with Françoise and Mahé who teach it. Nädì sodhana is generally translated as "alternate nostril breathing", because the practitioner inhales or exhales through one nostril while the other is blocked.

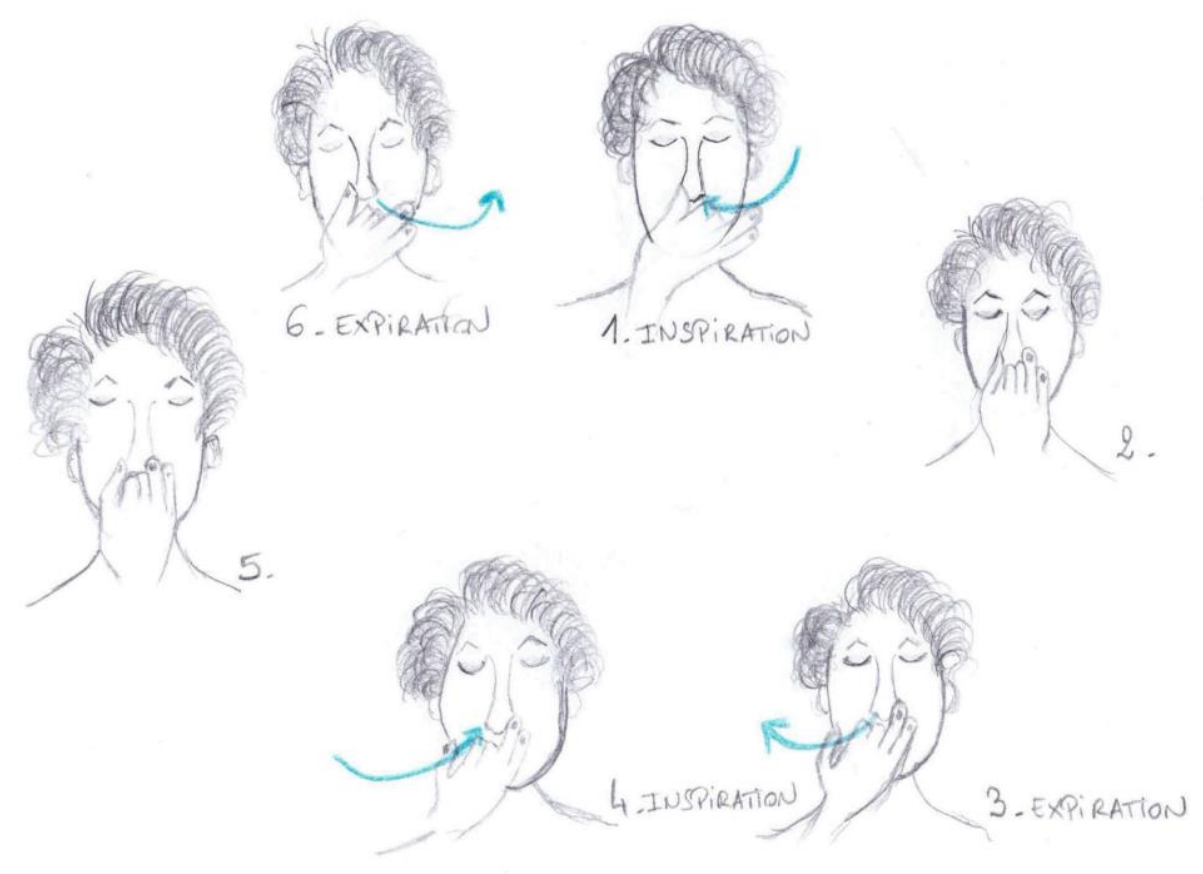

Figure 1: Representation of a complete cycle of nādī sodhana, retention (2 and 5) after inspiration is not systematic Source: author 2019

\footnotetext{
${ }^{7}$ The other people moved, one was pregnant at the second meeting, another stopped yoga.

8 In France as in Switzerland, it is possible to meet teachers for whom the "spiritual" dimension of yoga is related to mantra songs, prayers... It is not necessary to see in this division a cultural characteristic that would be inaccurate.

${ }^{9}$ Prānāyāma comes from the composition of two Sanskrit terms: prāṇa and āyāma. Prāna could have diverse meanings: "breath", "air", "energy" or "life force". The verb āyāma means "to extend". According to this etymology, prāṇāyāma is then similar to a method for extending the breath, or even suspending it, and is characterized by a set of functional techniques. Today, prānāyāma is often limited to breathing techniques.
} 
In concrete terms (see illustration above), the inspiration begins with the right nostril while the thumb closes the left nostril (1). The breath is eventually held (2) and then exhaled by the left nostril while the annular closes the right nostril (3). The air is breathed in again by the left nostril (4), which may be held (5), and then exhaled by the right nostril (6). These four or six movements constitute a breathing cycle.

In practice, depending on the schools and the courses, the technical details of learning $n \bar{a} d \bar{\imath}$ shodhana can vary. In this case, Françoise teaches it by letting the practitioners free of choosing the duration of the inhalation and exhalation times as well as a point of concentration in the body, while Mahé generally uses a metronome and doubles the exhalation time in comparison to inspiration. In ancient texts, $n \bar{a} d \bar{l}$ shodhana is often explained by an expiration twice longer than an inspiration. These differences in technical achievement made it possible to establish four variations of the exercise in order to try to study the influence of learning on the physiological results obtained ${ }^{10}$.

\section{Results}

After the double analysis of data, concordances and dissonances between objective measures and subjective perceptions emerged and highlighted the different levels of practice. The classical typology of sports science concerning the learning of a technique has been used to classify practitioners according to their level: beginner, intermediate or advanced. Among the practitioners, six persons were classified as beginners, seven as intermediates and eight as advanced.

This typology demonstrated first of all, that there was not necessarily a correlation between the number of years of practice and the level of the person. Even though some people have practiced yoga for many years and are able to perform very advanced postures, they have not yet acquired good body awareness allowing them to identify their sensation correctly. Thus, they were not placed in the advanced group because of physiological results or a poor correlation between their physiological data and discourses. Nevertheless, other people with a regular practice (at least three times a week) started two or three years ago may belong to the intermediate or advanced group.

\section{Beginners: practitioners who pay attention to the technique and the relaxation}

Thanks to the explanation interviews, it was possible to notice that beginners think a lot about their technical gesture (the position of their body, the counting of the cycle of nādi shodhana) and pay special attention to the instructions given. It was difficult for them to stay in the same posture, crossed-legs on the floor, for two hours. While they are rather talkative about the technique, there are sometimes discrepancies between the discourses and the physiological results obtained. In fact, many people feel that they have not been able to modulate their breathing in some exercises when data analysis shows the opposite. In their discourses, their vocabulary indicated that they were unable to do so.

Saraswati (2009) argues that even a beginner of nādi shodhana would be able to experience relaxation effects. However, any new learning generates stress, because of the energy required to concentrate on all the details of the execution of the technical gesture, especially if the person finds himself/herself in an exceptional situation, as in the case of experiment. Indeed, among the

\footnotetext{
10 In concrete terms, each meeting lasted between two and three hours and took place as follows: 1) watching a 3-minute film on yoga during which heart and breathing rates were recorded. The objective was to record unconscious breathing, 2) four exercises from $n \bar{a} d \bar{\imath}$ shodhana: a) the first with no indication of inhalation time and exhalation time, but with full lung retention (as shown in Figure 1), b) the second with imposed times: inhalation over 5 times and exhalation over 10 times, c) the third with inhalation over 7 times and exhalation over 14 times, d) finally, the last exercise from $n \bar{a} d \bar{\imath}$ shodhana without imposed time, but with a concentration point on the heart. 3) explicitation interview 4) semi-directive interview.
} 
beginners met, it appeared that the exercises that were not known generated significant stress (faster heart rate) and as a result, the physiological data did not reveal any dominance of the parasympathetic system. However, all beginners reported feeling "well" and more "relaxed" after these exercises. In this case, there is a discrepancy between the physiological results and the subjective discourse on this feeling.

In addition, beginners appear to have less consistent results. A second experiment conducted six-months later showed that progress was significant only for those of the group who practiced at least three times a week. While for the other groups, the results did not show significant progress. Thanks to the sport science studies on learning, it is possible to interpret these results in terms of performance. Indeed, a performance is obtained when it has become constant, that is, when the gesture is stable (Marin, Danion, 2005).

\section{Intermediate: a good connection between body awareness and discourses}

Intermediaries have well assimilated the gesture, they know how to count the number of cycles without making mistakes, they can remain seated without difficulty and do not feel disturbed by new exercises. However, their performance varies according to outside (noise, presence of others) and inside (fatigue, stress) circumstances and depends on the moment of the day. As Clelia says: "I was well focused, well relaxed, I felt comfortable, and I feel better now. Last time, I remember, I was really tired because we had seen each other at the end of the day" (Clelia, 32 years old, practitioner, Swiss). Generally, intermediaries are not able to perform all the exercises. They explore, try to respond to the instructions by adapting their skills to a new situation, without always succeeding.

Here is the example of Iris who is well aware of the working of her body. I observed a close correlation between her speech and her physiological results. For example, she felt "embarrassed during an exercise" because she "forced her exhalation, she was out of breath". In observing the details of the breathing rate curve on this exercise, I observed the same thing. However, Iris adds a particularity, which is often the case with intermediates, she states that she "has observed that [her] heart rate corresponds to [her] breathing rate when she breathes smoothly. [...] [She] thinks that [her] heartbeat corresponds to a second" (Iris, practitioner, 49 years old, French). However, the analysis of her heart rate does not allow to reach this conclusion, because such a regularity in the heart rate is almost impossible. Here, Iris has established a link between feelings and belief. She also remarks that she "doesn't know if it's true". As with Iris, the intermediates' discourse is much more focused on well-being, which is expressed through sensations of "cold", "heat", "light", "energy in motion".

\section{The advances: gesture incorporation and discourse appropriation}

The advanced are recognizable by their ability to adapt to new situations, their stability and consistency in both the gesture and the reproducibility of the results. These people have acquired a greater ability to modulate their breathing, they know precisely where they have failed or succeeded. Their parasympathetic system seems to dominate and their physiological results match the description of their physical sensations.

"I focus on the flow of breath, but often it's more of an imaginary fixation, it's like a third eye. The point of concentration helps me, it's like in meditation, it keeps me from getting lost. I'm trying to focus on my prānāa, on the vital energy. " (Maxence, practitioner, 37 years old, French)

Like Maxence, the advanced describe fewer feelings of "relaxation" and the evocation of the technical gesture is absent from their speech. They sometimes evoke their feelings, but borrow a 
vocabulary specific to yoga. Here, there is a reappropriation between technical vocabulary, body awareness and incorporation.

Thus, being aware of the realization of a technical gesture depends on the phase of the learning process and has an impact on both physiological results and discourses. The more advanced the person is, the more developed his/her bodily awareness is and the less attention he/she pays to the technique or gesture itself, his/her discourses becomes more pictured. Beginners express their well-being through the feeling of being "relaxed", intermediates describe it as the pleasure of "feeling the passage of air", "holding their breath" or "staying focused", and advanced use technical terms. Why are there such differences?

\section{Discussion about differences and similarities}

Going back to the initial question, it appears that if yoga practitioners say they feel "good" after a breathing practice, it is because the parasympathetic system predominates in most cases, at least for the intermediates and the advanced. However, why do beginners say the same thing without the physiological results allowing such a conclusion? Here, the social sciences provide interesting insights and on can perceive the strength of the teacher's influence.

\section{The refinement of body awareness: characteristic of yoga}

One of the characteristics of learning yoga lies in the growing awareness of the body linked to the amplification given to the attention given to one's body. In yoga, practitioners become aware of their body perceptions, movements, body functioning, emotions. Thereafter, by repeating the sensations, reactions and movements of the body, the practitioner focuses on a part of the body or on his/her breathing. This new awareness is the consequence of learning of new movements, of discovering new sensations.

How does this bodily attention affect the well-being? For one and a half hours, the practitioner is led by the teacher to cut himself off external solicitations to get in motion and listen to one's body. Here is the example of the final relaxation (named savāsana) which appears particularly relevant by the redundancy of certain terms, in particular by the use of relaxation. In concrete terms, every yoga class ends with this posture lying with your back on the floor, eyes closed, arms and legs spread the "width of the mat".

Extract from a field notebook of a final relaxation at the Sivananda course given in ashram in September 2013.

"Now, savāsana, put your legs a few centimetres apart. Be sure to put yourself in a good posture, with your body fully aligned. Do not move during the entire relaxation.

Try the autosuggestion, repeat the formula in your head: "I relax my feet, I relax my feet, my feet are relaxed".

"I relax my calves, I relax my calves, my calves are relaxed".

The same formulation is used for knees, thighs, hips, lower back, middle and upper back.

"Relax more and more.

Relax your abdomen, chest, hands, forearms, arms, feel the gravity in your arms".

More and more silence between indications.

"The neck, shoulders, head, scalp and face, your internal organs are relaxed: the liver, stomach, spleen are relaxed.

My mind is relaxed, my eyes are relaxed. I feel gravity in my head.

Now connect with your breath. Your breath follows your own rhythm.

I relax my mind, my mind is relaxed.

I relax my heart, my heart is relaxed. I relax my mind and nerves, go deeper and deeper." 
relax, relax, relax, rreeeelllaaaaaxxxx."

Phrased slower and slower, spaced between indications. Tone of the voice decreasing. Then 5 minutes of relaxation without words.

In this final relaxation that lasted about ten minutes, "relaxed" was used thirty-six times. The description of this sequence highlights the importance given to listening to one's body, sensations and emotions, as well as the way in which the teacher leads the practitioner to become attentive to the functioning of his body. This incentive to relaxation demonstrates the performative nature that the teacher can have on the body and the sensations of the practitioner.

\section{The performative role of the teacher}

From this example, it is impossible to assess that the teacher induces a feeling of well-being, but rather that he/she acts on the interpretation of the sensations actually felt. While the technique affects physiological well-being, the teacher influences the understanding and translation of this well-being. Beginners have a less developed body awareness and probably have more difficulty recognizing and interpreting their physical sensations. Intermediates and advanced students can feel themselves relaxing, they know how to identify them, yet the teacher also plays a performative role in the interpretation, the words that qualify these feelings.

As Blacking (1977) points out with regard to communication linked to the body, several difficulties arise in interpreting discourses on sensations, such as well-being: 1) for the subject to name and identify them, 2) to be sure that people understand the same thing, 3) in the ability to talk about feelings according to age, sex, education. Despite these biases, several authors, including Becker (1963) or Hauser (2013), have shown that there are similarities between the vocabulary used concerning certain sensations, within the same social group, thus highlighting thus the influence of social, learning and socialization in the interpretation of somatic states. As in any learning, there is in yoga a common vocabulary for all practitioners, yet there is also a direct influence of the teacher on the interpretation of the sensations.

According to the teacher, and therefore according to the speeches accompanying the technical learning, some practitioners give a more physical or a more symbolic connotation to the breath. While beginners use the verbatim used by the teacher to describe their body and breath, intermediaries are more imaginative in associating their breathing with "moving colours", for example. Advanced students use a much more symbolic vocabulary to describe their sensations and body perceptions. For example, they no longer talk about breathing, but use the term prāna.

On this point, the comparison between teachers seems more relevant. Françoise, whose discourse is much more about spiritual, and Mahé both use the term prāna when they teach these techniques. The Sanskrit concept of prāna refers to three meanings: a "life force", an "energy" or a "breath, air". Thus, the translation of this term may vary.

For Françoise, it is a "vital force" which translates into "a feeling of holistic union between body and mind [...] and between body and all the elements of the universe, of the environment. We are only parts of a prāna that circulates between all living beings" (Françoise, teacher, 53 years old, Swiss). Mahé defines it as "an energy that circulates in the body. It is the breath, the air" (Mahé, teacher, 37 years old, French), giving it a more physical meaning close to the Latin notion of "energia", as a "force in action". Catherine (Françoise's student for four years) testifies:

"I felt perfectly relaxed, I succeeded in all the exercises, even the ones I'm not used doing. I know that I am comfortable in it, when I feel the prāna in me, it is the moment when everything is flowing. Often, I know that it activates the energies because I feel some sort of tingling in the point between the two eyes. I love this feeling of fullness, 
this harmony in my body and between my body and the environment. " (Catherine, 57 years old, practicing, Switzerland)

Catherine seeks to awaken the feelings of relaxation that she associates with the movement of the prāna. For her, the prāna refers to this "feeling of harmony in her body and with her environment", that Françoise describes in her classes. During the interviews, Mahé's students defined prāna, in a more physical and functional sense as synonymous with "breathing" or "bodily energy", while Françoise's students referred to it as a "vital force", a "union between oneself and the environment/god/others". Thus, the teachers influence the interpretations of sensations and conceptions of breath, body or well-being.

Similarly, the interpretation and understanding of this well-being varies according to the naming of well-being in yoga practices and to the teachers' discourses. Mahé's students refer to this well-being as a "relaxation of muscles", "tension" while Françoise's students express what they feel "at present".

\section{Conclusion}

Depending on his/her level, the practitioner does not focus on the same sensations, on the same parts of the body to perform the technical gesture. These different categories show that the more advanced people are, the more relevant become the correlation between the discourse on sensations and physiological data. It is clear that the beginner requires a lot of energy to understand and acquire the technique, resulting in more detailed gestural descriptions. The intermediate has incorporated the technical gesture and is able to modulate it, yet there is no reproducibility from one time to another, insisting on one's perceptions and feelings.

Thus, if a yoga practitioner can learn to master methods that help him regulate his/her breathing and act on hi/hers feeling of relaxation. However, there is also a social construction, an influence of the teacher not only on the possibility of refining his bodily awareness, thus being able to accurately identify his feelings of well-being, but also on the way in which this well-being is translated and interpreted. To sum it up, there is a co-construction between setting in motion, setting in words, body awareness and their interpretation during the learning of a body technique.

This reflection sheds light on the links between yoga and well-being through the learning of body awareness and the interpretation of sensations. This felt and expressed well-being often appears in the anthropological interviews of other practitioners. If health and stress are mainly mentioned as a reason to begin yoga, the well-being experienced during and after the class remains a motivation to return to the mat. Indeed, beyond the moments dedicated to the practice, the practitioners are convinced that the learning of these techniques helps them in their daily life, in particular to manage their stress, their positive or negative emotions better. Many people report that their families and friends are observing changes in their reactions. Others mention a better concentration, a greater efficiency in their work. Thus, this individual well-being is reflected in their everyday life, in their relationships with others, in their work.

This interdisciplinary approach would benefit from further development. For example, the European and Indian contexts could be compared in order to find out whether there are cultural differences. A randomized study could also be envisaged to further explore the results.

\section{REFERENCES}

Alter, Joseph. 2004. Yoga in modern India, the body between science and philosophy. Princeton: University Press.

Altglas, Véronique. 2005. Le Nouvel Hindouisme occidental. [New Western Hinduism]. Paris: CNRS Éditions.

Becker, Howard S. 1963. Outsiders. Studies in the Sociology of Deviance. Paperback. 
Bhimani, N.T, Kulkarni, N.B, Kowale, A, Salvi S. 2011. "Effect of prāṇāyāma on stress and cardiovascular autonomic tone and reactivity," National Journal Of Integrated Research in Medicine 2(1): 48-54.

Birch, Jason. 2011. "The Meaning of hatha in Early Hathayoga," Journal of the American Oriental Society 131 (4): 527-554, www.jstor.org/stable/41440511.

Blacking, John. 1977. Anthropology of the body. Londres, New York, Academic Press.

Brown, Kirk. W., Ryan, Richard. M. 2003. "The benefits of being present: Mindfulness and its role in psychological well-being." Journal of Personality and Social Psychology 84(4): 822-848, DOI: 10.1037/0022-3514.

Cameron, Oliver. 2001. "Interoception: the inside story - a model for psychosomatic processes." Psychosom. Med (63): 697-710, DOI:10.1097/00006842-200109000-00001.

Cowen, Virginia S., Adam,s Troy B. 2005. "Physical and perceptual benefits of yoga āsana practice: results of a pilot study," Journal of bodywork and movement therapies 9: 211219, DOI: 10.1016/j.jbmt.2004.08.001.

De Michelis, Elisabeth. 2005. A History of Modern Yoga, Patañjali and Western Esotericism. London, New York: Bloomsbury Academic.

Dinesh, T. 2013. "Effect of 6 weeks of kapālabhāti prānāyāma Training on Peak Expiratory Flow" Scholars Academic Journal of Biosciences 1(4): 111-114.

Hauser, Beatrix. 2013. Yoga Traveling: Bodily Practice in transcultural Perspective. New York: Springer.

Hoyez, Anne-Cécile. 2006. L’Espace-Monde du Yoga. Une géographie sociale et culturelle de la mondialisation des paysages thérapeutiques. [The World-Space of Yoga. A social and cultural geography of the globalization of therapeutic landscapes]. $\mathrm{PhD}$ in University of Rouen.

Jerath, R., Barnes, V.A., Dillard-Wright, D., Jerath, S., Hamilton, B., 2012. "Dynamic change of awareness during meditation techniques: neural and physiological correlates," Frontiers in human neuroscience 6, DOI: 10.3389/fnhum.2012.00131.

Maas, Philipp. 2013. “A Concise Historiography of Classical Yoga Philosophy,” Historiography and Periodization of Indian Philosophy, Éditions Eli Franco, Vienne: De Nobili Series.

Mallinson, James, Singleton, Mark. 2017. Roots of Yoga. London: Penguin Books.

Marin, Ludovic, Danion, Frédéric. 2005. Neurosciences: contrôle et apprentissage moteur. (Neuroscience: motor control and learning). Paris: Éditions Ellipses.

Mehling, W. E., Gopisetty, V., Daubenmier, J., Price, C. J., Hecht, F. M., Stewart, A. 2009. "Body Awareness: Construct and Self-Report," PLoS ONE 4(5): 5614, doi: 10.1371/journal.pone.0005614.

Newcombe, S. 2019. Yoga in Britain. Streteching, Spirituality and Educating Yogis. Sheffield: Equinox.

Price, C. J., Hooven, C. 2018, "Interoceptive Awareness Skills for Emotion Regulation: Theory and Approach of Mindful Awareness in Body-Oriented Therapy (MABT)," Frontiers in psychology 9 (798), doi: 10.3389/fpsyg.2018.00798.

Quidu, Mathieu, Favier-Ambrosini, Brice. 2014. "L'articulation des données en première et troisième personnes. De la genèse d'une méthodologie originale en Science du sport," [The articulation of data in first and third persons. The genesis of an original methodology in Sport Science]. Intellectica, DOI : https://doi.org/10.3406/intel.2014.1031.

Samuel, Geoffrey. 2008. The Origins of Yoga and Tantra, Indic religions to the Thirteenth Century. Cambridge: Cambridge University Press.

Saraswati, Niranjanananda. 2009. Prāṇa and prāṇāyāma. Bihar, India: Yoga Publications Trust.

Singh, S, Gaurav, V., Parkash, V. 2011. "Effect of 6 weeks nādī-shodhana prāṇāyāma training on cardio-pulmonary parameter," Journal of Physical Education and Sports Management 2(4): 44-47. 
Singleton, Mark. 2010. Yoga Body. The origins of modern posture practice. Oxford: Oxford University Press.

Strauss, Sarah. 2005. Positioning Yoga: balancing acts across cultures. Oxford: Berg Publishers.

Subbalakshmi, N. 2005. "Immediate effect of nādī shodhana prāṇāyāma on some selected parameters of cardiovascular, pulmonary and higher functions of brain," Thai Journal of Physiological Sciences 18 (2): 10-16.

Tripathy, M., \& Sahu, B. 2019. "Immediate Effect of Nadi Shodhana Pranayama on Blood Glucose, Heart Rate and Blood Pressure". Journal of American Science, 15(5).

Varela, Francisco., Thompson, Evan., Rosch, Eleanor. 1993. The Embodied Mind: Cognitive Science and Human Experience. MIT Press. ISBN 978-0-262-72021-2.

Vermersch, Pierre. 1994. L'Entretien d'explicitation. [Explicitation interview] Paris: ESF éditeur.

White, David G. 1998. The Alchemical Body, Siddha traditions in Medieval India. Chicago: Éd. University of Chicago Press.

\section{ABOUT THE AUTHORS}

Caroline Nizard: Researcher affiliate, Institut d'histoire et anthropologie des religions, Lausanne University, Switzerland. 